\title{
INTERNAL CONSISTENCY OF THE EDUCATIONAL VALUE SCALE FOR GREEN OUTDOOR SETTINGS - THE CASE OF EDUPARK APP
}

\author{
Margarida M. Marques, Lúcia Pombo, University of Aveiro, Portugal
}

\begin{abstract}
The purpose of this paper is to analyse the internal consistency of an Educational Value Scale (EVS) to be used to assess individuals' subjective perception of an educational app ability to support relevant learning in green outdoor settings. In this work, the EVS is presented as a scale with 12 items and data is aggregated and analysed to contribute to an empirical validation of the educational value construct. In this study, the analysis focuses a scale desirable psychometric property, the reliability, which is analysed through a robust Cronbach's $\alpha$ estimation. Data for analysis is collected from a total of 924 responses to a questionnaire from students (of all school levels) and their teachers, after using the EduPARK app during a one-year face-to-face survey. Results reveal that the scale has internal consistency for teachers and older students $\left(2^{\text {nd }}, 3^{\text {rd }}\right.$ Cycle of Basic Education and Secondary teaching students). This study is an initial effort to validate an EVS, which can be helpful to researchers developing and accessing educational apps and to educators selecting educational apps to integrate in their teaching practices.
\end{abstract}

Keywords: Educational value scale (EVS), mobile learning, educational app assessment, Robust Cronbach's alpha, internal consistency, reliability, EduPARK app, empirical study.

\section{Introduction}

The ubiquity of mobile phones and its use for educational purposes has been a growing field of research with positive results in learning. Frequently, mobile learning literature reported student gains in cognitive and skill-based outcomes, as well as increased motivation and engagement (Zydney \& Warner, 2016).

There is an increasing offer of educational mobile apps; however, their ability to promote learning is seldom demonstrated, and few trustworthy information on their quality is available. For example, the popularity criteria for app selection may not be the best option, as the same app can yield different educational gains in different educational contexts. 
Marques, M. M., \& Pombo, L.

Internal Consistency of the Educational Value Scale for Green Outdoor Settings - The Case of EduPARK App

Hence, for teachers and parents the task of deciding which educational app(s) to use with their students or children is not simple. Thus, they could highly benefit from the wide application of a scale to evaluate this type of software.

In academic and industry, the development of educational apps for mobile learning can benefit from the target audience's feedback, as users' perceptions, for example about the usability, acceptance and improvement, can contribute to refine software prototypes (Pombo, Marques, Afonso, Dias, \& Madeira, 2019). The use of scales to evaluate apps' educational value is also relevant. Evaluation tools are frequently extensive and difficult to complete, as the evaluation framework developed by de Freitas \& Olivier (2006), especially if younger students' feedback is included in the study. The same app can promote learning in a given age group or audience with certain characteristics, but not for another.

Internal consistency is associated with a desirable psychometric property, reliability, which is usually analysed though Cronbach's $\alpha$ (Hair, Black, Babin, Anderson, \& Tatham, 2010). The purpose of this study is to analyse the internal consistency of an Educational Value Scale (EVS) to be used to assess users' subjective perception of an educational app ability to support relevant learning in green outdoor settings. For app consumers, the contribution of this scale relies in supporting educational practitioners in designing instruction strategies and materials for learners, taking advantage of mobile devices affordance. Furthermore, EVS can be useful for researchers and educational software developers to assess their products and decide if further improvements are needed.

The paper is structured in the following sections: (a) Methods, with the description of the procedure of the EVS development and analysis of its internal consistency through the robust Cronbach's $\alpha$, considering data from 924 questionnaires filled in by students and their teachers after using the EduPARK app in a green outdoor setting; (b) Results and their discussion in the light of literature, implications for research and practice, research limitations and proposals of future research.

\section{Methods}

This section describes how the EVS was created and its internal consistency analysed. First the EduPARK app is presented, as data was collected in reference to this particular mobile app. Follows a brief description on how the scale items, presented in Table 2, were produced. Finally, the procedure to analyse the internal consistency is also presented. 


\section{The case of EduPARK app}

The EduPARK app was developed by the EduPARK Project (http://edupark.web.ua.pt/?lang=en) multidisciplinary team, involving researchers from the University of Aveiro (Portugal). The project aimed at creating attractive and effective strategies for interdisciplinary learning, relying on the development of an interactive mobile augmented reality app that supports geocaching activities a green outdoor setting - the Infante D. Pedro Park, in Aveiro. The City Council allowed the installation of plant identification plaques in the city park with augmented reality information in images, audios, videos, schemes, and 3D plant leaves.

The app can be used autonomously, and at any time, through the game mode or explore freely mode, promoting authentic learning so that visitors can enjoy a healthy walk while learning. The game includes several learning guides for different target groups: teachers and students from Basic to Higher Education, and also visitants and general public, in a lifelong learning perspective, as the tourist guide is also offered in English. The guides integrate multidisciplinary issues under the Portuguese National Education Curriculum and propose interdisciplinary questions articulated to educational challenges along the park. The goal is to accumulate points by answering correctly the questions, visualizing augmented reality markers that help to answer questions, and finding virtual caches in a logic of treasure hunt. Further information about the game and app can be found in Pombo and Marques (2019).

The EduPARK app development follows a design-based research methodology, with successive refinement cycles, based on the users' feedback. The project organised activities for students, teachers and visitors to gather a convenience sample to collect systematic data. The activities occurred in the Aveiro Park and comprise: (a) a small introduction on the activity and some instructions on how to use the EduPARK app to play; (b) the actual game playing with the EduPARK app by groups of (usually) three or four students accompanied by an adult (a teacher, other school staff or an EduPARK team member), and (c) the filling in of a paper questionnaire (with the EVS, as described in Pombo \& Marques, 2019) and the leader-board construction and announcement to participants, with small prizes distribution. The average response time to que questionnaire was 10-15 minutes.

The data collection occurred from March 2018 to April 2019. Table 1 reveals that a total of 44 activities for 1007 students, from the $1^{\text {st }}$ Cycle of Basic Education (CBE) to Secondary teaching, and 122 accompanying adults, were organised both in formal and non-formal educational contexts. Five activities (out of 44) were mixed in what concerns students' school level (both $1^{\text {st }}$ and $2^{\text {nd }} / 3^{\text {rd }} \mathrm{CBE}$ ). 
Marques, M. M., \& Pombo, L.

Internal Consistency of the Educational Value Scale for Green Outdoor Settings - The Case of EduPARK App

Table 1: Relation of number of activities, participant students, and accompanying teachers in the EduPARK activities, per school level

\begin{tabular}{lcccc}
\hline & $1^{\text {st }}$ CBE & $2^{\text {nd }} / 3^{\text {rd }}$ CBE & Secondary Teaching & Total \\
\hline Number of activities & $23(5$ mixed $)$ & $21(5$ mixed $)$ & 3 & 42 \\
Number of students & 476 & 396 & 74 & 1007 \\
Number of teachers & 91 & 24 & 7 & 122 \\
\hline
\end{tabular}

\section{Developing EVS}

The EVS was developed under the EduPARK project (as described in above), which aimed to analyse the impact of the EduPARK app on different dimensions: (a) learning value; (b) intrinsic motivation; (c) engagement; (d) authentic learning; (e) lifelong learning; and (f) conservation and sustainability habits. For that purpose, two educational researchers, with expertise in mobile learning in green outdoor settings, analysed literature associated with the assessment of the above-mentioned dimensions (Crick \& Yu, 2008; Erdogan, Ok, \& Marcinkowski, 2012; Martínez, Aracón, \& Hita, 2014; Simões \& Alarcão, 2011; Walker \& Fraser, 2005) to propose a set of items for the EVS. The set of items was revised in several rounds to remove, add and/or adapt items so they could measure the intended construct: the educational value based on the six dimensions mentioned above.

The educational researchers had the experience of using, under the same project, the System Usability Scale (SUS). This scale was developed by Brooke (1996) to quickly and easily collect a user's subjective rating of a product's usability. According to Bangor et al. (2008), who aggregated and analysed data from 2,324 questionnaires collected over 10 years, SUS is a widely used instrument in usability studies, with a high reliability: 0.91. In a similar way, EduPARK educational researchers decided to attempt to develop a scale to quickly and easily collect users' subjective rating of the educational value of an app for outdoor green settings. Taking this into account, two items from each of the abovementioned six dimensions of educational value should be included in the scale. In the iterative process of items generation and negotiation, 12 items earned both experts' agreement and were selected for inclusion in the EVS (see Table 2). Similarly to SUS, positive and negative items were alternated, to make sure the respondent reads and understands each statement before deciding whether or not to agree with it. The items were scaled in Likert format anchoring from 1 - strongly disagree to 5 - strongly agree for the analysis. 
Table 2: $\quad$ Educational Value Scale (EVS) items

\section{EVS item}

1. This app helps you learn more about topics we study at school.

2. This app shows information in a confusing way.

3. I feel motivated to learn when I use this app.

4. I do not feel like using this app to learn.

5. Even in the difficult quiz-questions, I try to find the right answers.

6. Sometimes I respond randomly (without thinking).

7. This app shows real-world information that helps you learn.

8. I will quickly forget what I have learnt from this app.

9. Park visitors can learn from this app.

10. This app promotes learning only in a school context.

11. This app makes me feel like talking to others about nature protection.

12. This app does not help to realize that it is important to protect nature.

\section{Internal consistency}

Internal consistency of the EVS was assessed as a measure of scale reliability. Cronbach's coefficient $\alpha$ is one of the most widely adopted measure of the lower bound of the reliability (Hair et al., 2010). However, as this $\alpha$ has received some criticism in the literature, Zhang and Yuan (2016) robust Cronbach's $\alpha$ estimation procedure was followed to control the influence of outlying observations and leverage observations. In this procedure, three different plots are analysed to determine the adequate downweigh rate $(\varphi)$ to compute Cronbach's $\alpha$ for a dataset.

Although the Cronbach's $\alpha$ is usually computed for data collected on a particular occasion (Taber, 2018), data aggregation from multiple studies collected through standardized scales has also been conducted before (Bangor et al., 2008). Hence, a robust Cronbach's $\alpha$ was estimated for all the 924 cases aggregated in one dataset and for four subpopulations within it, originated from 42 data collection events. An $\alpha$ value which exceeds 0.7 can be considered acceptable (Hair et al., 2010). However, other authors consider the value 0.6 as the lower bound of reliability acceptance, particularly in early stage of research (Griethuijsen et al., 2015; Nunnally, 1967).

\section{Results and discussion}

This section presents and discusses, in the light of literature, the internal consistency of EVS. Research limitations are discussed and future directions are proposed.

Table 3 presents the estimated Cronbach's $\alpha$ for the entire dataset (924 cases) and for the four considered subpopulations within it. Complementary data, such as standard deviation (SD), confidence intervals (CI) and used downweigh rates $(\varphi)$ are also presented. 
Marques, M. M., \& Pombo, L.

Internal Consistency of the Educational Value Scale for Green Outdoor Settings - The Case of EduPARK App

Table 3: Estimated Cronbach's coefficient a for the entire dataset and for four subpopulations within it.

\begin{tabular}{lccccc}
\hline & Total & $1^{\text {st }} \mathrm{CBE}$ & $2^{\text {nd }} / 3^{\text {rd }} \mathrm{CBE}$ & $\begin{array}{c}\text { Secondary } \\
\text { Teaching }\end{array}$ & $\begin{array}{c}\text { Accompanying } \\
\text { Teachers }\end{array}$ \\
\hline Robust a & 0.732 & 0.653 & 0.738 & 0.716 & 0.818 \\
SD & 0.018 & 0.035 & 0.030 & 0.056 & 0.040 \\
Cl & 0.697 to 0.767 & 0.584 to 0.722 & 0.680 to 0.796 & 0.606 to 0.826 & 0.740 to 0.896 \\
$\varphi$ & 0.00 & 0.00 & 0.07 & 0.10 & 0.10 \\
\hline
\end{tabular}

Considering 0.7 as the $\alpha$ value for an acceptable reliability (Hair et al., 2010), the $\alpha$ for $2^{\text {nd }} / 3^{\text {rd }}$ CBE (0.738), Secondary Teaching (0.716), Accompanying teachers (0.818) and total data set (0.732) can be considered from acceptable to good. This indicates that EVS has achieved an acceptable or good internal consistency. On the other hand, $\alpha$ value for $1^{\text {st }} \mathrm{CBE}(0.653)$ falls just below the common acceptable threshold, accordingly to Hair and colleagues (2010), or this $\alpha$ value is just within the lower bound of acceptance (Griethuijsen et al., 2015; Nunnally, 1967). This result might be explained by the age of respondents, as younger students (age range from 6 to 11) may lack the maturity level required to truly understand and answer correctly the scale items. For example, $43.7 \%$ of these students attended school year 2 , so their reading skills were still in an initial phase of development, with notable difficulties in understanding the scale items. Furthermore, the alternation between the positive and negative wording of items can lead to misinterpretation and difficulty in reversing responses from negative to positive ones. Users can forget to reverse their score accidentally agreeing with a negative item when they meant to disagree. These possible explanations are consistent with some other studies (Kortum, Acemyan, \& Oswald, 2020; Ribeiro, 2020). Based on this result it is highly recommended to revise EVS items and graphic presentation of Likert scale to turn it more suitable for this school level.

The higher $\alpha$ value was achieved in the teachers' subpopulation, as they are adults from the educational context, frequently use to answer questionnaires, for example, in the mandatory continuous professional trainings.

As implications for research and practice, this study intends to initiate an effort of scale validation. The EVS can become a useful instrument to support researchers in developing and accessing educational app, as it can be used as a standardized educational value questionnaire. Standardized questionnaires allow the collection of systematic data supporting higher objectivity, replicability and quantification of results, among other advantages (Sauro \& Lewis, 2012). Likewise, an EVS can support educators in the selection process of the educational apps suitable for their teaching practices, as if EVS becomes widely used, apps that achieve higher EVS scores with students of their education level are expected to be more suitable for their classes. 
Research limitations are related to the fact that empirical analysis was made on the Portuguese version of the EVS. Although the items translation to English was made by experience researchers, the participation of bilingual translator and back-translation method would improve the English version of the EVS. Likewise, eventual cultural differences were not taken into consideration.

For future research, it is recommended to adapt and to empirically analyse the internal consistency of the EVS scale for $1^{\text {st }} \mathrm{CBE}$ students, turning it more suitable for this study level, in terms of language, graphic presentation and use of always positive worded items. Moreover, the scale relevance will increase as educational app developers use this tool as a standardized questionnaire for Educational value evaluation.

\section{References}

Bangor, A., Kortum, P. T., \& Miller, J. T. (2008). An Empirical Evaluation of the System Usability Scale. International Journal of Human-Computer Interaction, 24(6), 574-594. https://doi.org/10.1080/10447310802205776

Brooke, J. (1996). SUS: A “quick and dirty” usability scale. In P. W. Jordan, B. Thomas, B. A. Weerdmeester, \& A. L. McClelland (Eds.), Usability Evaluation in Industry. London: Taylor and Francis.

Crick, R. D., \& Yu, G. (2008) Assessing learning dispositions: is the Effective lifelong learning inventory valid and reliable as a measurement tool? Educational Research, 50(4), 387-402. https://doi.org/10.1080/00131880802499886

Erdogan, M., Ok, A., \& Marcinkowski, T. J. (2012) Development and validation of Children's Responsible Environmental Behavior Scale. Environmental Education Research, 18(4), 507-540. https://doi.org/10.1080/13504622.2011.627421

Frasca G. (2004) Videogames of the oppressed: critical thinking, education, tolerance, and other trivial issues. In N. Wardrip-Fruin \& P. Harrigan (Eds.), First Person: New Media as Story, Performance, and Game (pp. 85- 94). MIT Press, Cambridge, MA.

de Freitas S., \& Oliver M. (2006). How can exploratory learning with games and simulations within the curriculum be most effectively evaluated? Computer \& Education, 46, 249-264. https://doi.org/10.1016/j.compedu.2005.11.007

Griethuijsen, R. A. L. F., Eijck, M. W., Haste, H., Brok, P. J., Skinner, N. C., Mansour, N., Gencer, A. S., \& BouJaoude, S. (2015). Global patterns in students' views of science and interest in science. Research in Science Education, 45(4), 581-603. https://doi.org/10.1007/s11165-014-9438-6 
Hair, J. F., Black, B., Babin, B., Anderson, R. E., \& Tatham, R.L. (2010). Multivariate Data Analysis ( $7^{\text {th }}$ ed.). Upper Saddle River, NJ: Prentice Hall.

Kortum, P., Acemyan, C. Z., \& Oswald, F. L. (2020). Is It Time to Go Positive? Assessing the Positively Worded System Usability Scale (SUS). Human Factors: The Journal of the Human Factors and Ergonomics Society. https://doi.org/10.1177/0018720819881556

Martínez, C. C., Aracón, P. R., \& Hita, J. A. (2014). A scrutiny of the educational value of EFL mobile learning applications. Cypriot Journal of Educational Sciences, 9(3), 137146. http://hdl.handle.net/20.500.12020/386

Nunnally, J. C. (1967). Psychometric theory. McGraw-Hill.

Pombo, L. \& Marques, M. M. (2019). Learning with the augmented reality EduPARK game-like app: its usability and educational value for primary education. In K. Arai, R. Bhatia, \& S. Kapoor (Eds.), Computing Conference, 16-17 July (pp. 113-125). Springer. https://doi.org/10.1007/978-3-03022871-2_9

Pombo, L., Marques, M. M., Afonso, L., Dias, P. \& Madeira, J. (2019). Evaluation of a Mobile Augmented Reality Game Application as an Outdoor Learning Tool. International Journal of Mobile and Blended Learning, 11(4), 59-79. https://doi.org/10.4018/IJMBL.2019100105

Ribeiro, A. N. R. (2020). Projeto EduPARK: A beleza dos bancos de jardim para alunos do 1. ${ }^{\circ} C E B$ [EduPARK Project: The beauty of garden benches for students of the $1^{\text {st }} \mathrm{CBE}$ ]. (Masters dissertation in Primary Education and Mathematics and Natural Sciences of the 2nd cycle of Basic Education - Educational Technologies). University of Aveiro, Aveiro. Retrieved from http://edupark.web.ua.pt/publications

Sauro, J., \& Lewis, J. R. (2012). Standardized Usability Questionnaires. In J. Sauro, \& J. Lewis (Eds.), Quantifying the User Experience: Practical Statistics for User Research (pp. 185-240). Morgan Kaufmann. https://www.elsevier.com/books/quantifying-the-userexperience/sauro/978-0-12-384968-7

Simões, F., \& Alarcão, M. (2011). Avaliação da motivação intrínseca na aprendizagem: validação de duas escalas para crianças e adolescentes. Psico-USF, 16(3), 265-273. https://doi.org/10.1590/S1413-82712011000300003

Taber, K. S. (2018). The Use of Cronbach's Alpha When Developing and Reporting Research Instruments in Science Education. Research in Science Education, 48, 12731296. https://doi.org/10.1007/s11165-016-9602-2

Walker, S. L., \& Fraser, B. J. (2005). Development and validation of an instrument for assessing distance education learning environments in higher education: The distance 
education learning environments survey (DELES). Learning Environments Research, 8, 289-308. https://doi.org/10.1007/s10984-005-1568-3

Zhang, Z. \& Yuan, K. (2016). Robust Coefficients Alpha and Omega and Confidence Intervals with Outlying Observations and Missing Data: Methods and Software. Educational and Psychological Measurement, 76(3), 387-411. https://doi.org/10.1177/0013164415594658

Zydney, J. M., \& Warner, Z. (2016). Mobile apps for science learning: Review of research. Computers \& Education, 94, 1-17. https://doi.org/10.1016/j.compedu.2015.11.001

\section{Acknowledgement}

This work is funded by national funds (OE), through FCT - Fundação para a Ciência e a Tecnologia, I.P., in the scope of the framework contract foreseen in the numbers 4,5 and 6 of the article 23, of the Decree-Law 57/2016, of August 29, changed by Law 57/2017, of July 19 and under the project UIDB/00194/2020. 